\title{
Longitudinal movement of fish in response to a single-day flow pulse
}

\author{
Lisa C. Thompson • Sarah A. Cocherell • \\ Stephanie N. Chun • Joseph J. Cech Jr. • \\ A. Peter Klimley
}

Received: 1 October 2009/Accepted: 31 October 2010/Published online: 18 November 2010

(C) The Author(s) 2010. This article is published with open access at Springerlink.com

\begin{abstract}
We studied whether fish were displaced longitudinally downstream by a 1-day whitewater kayaking pulse flow release from Camino Dam on Silver Creek, a tributary of the South Fork American River, California. On 15 September 2004 flows were increased from a base flow of $0.48 \mathrm{~m}^{3} \cdot \mathrm{s}^{-1}$ to a peak of $18.48 \mathrm{~m}^{3} \cdot \mathrm{s}^{-1}$ by midday, and decreased back to base levels. Rainbow trout (Oncorhynchus mykiss) and brown trout (Salmo trutta) were observed in snorkel surveys before and after the pulse. Counts of youngof-the-year and juvenile trout were $26 \%$ and $9 \%$ lower after the pulse, respectively. Counts of adult trout were $12 \%$ higher. Six adult trout were radiotagged and were observed in the reach before, during, and after the pulsed flow. Our results suggest that most trout were able to remain in the study reach during the pulse, but that smaller fish may be more likely to be displaced downstream.
\end{abstract}

L. C. Thompson $(\bowtie) \cdot$ S. A. Cocherell $\cdot$ S. N. Chun •

J. J. Cech Jr. • A. P. Klimley

Wildlife, Fish, \& Conservation Biology Department,

University of California Davis,

1 Shields Avenue,

Davis, CA 95616-8751, USA

e-mail: 1cthompson@ucdavis.edu

Present Address:

S. N. Chun

Department of Water Resources,

3310 El Camino Avenue, Suite 110,

Sacramento, CA 95821, USA
Keywords Pulsed flow · Fish movement · Snorkel · Telemetry · Rainbow trout Oncorhynchus mykiss . Brown trout Salmo trutta

\section{Introduction}

Pulsed flows are relatively rapid increases in flows followed by relatively rapid decreases in these flows, with flow fluctuations lasting minutes, hours, or days (Hunter 1992). Reasons for pulsed flows include: (1) generating electricity, (2) flushing streambeds, (3) providing additional water for downstream diversion for irrigation, (4) preventing reservoirs from flooding, and (5) facilitating human recreation such as rafting and kayaking. Pulsed releases for kayaking are frequently negotiated during Californian dam relicensing by the Federal Energy Regulatory Commission (FERC), and 7-fold changes in flow are not uncommon (Klimley et al. 2007). Remote river reaches may experience only a few days of pulses per year, but the impact of these infrequent pulses on fish are uncertain. Young-of-the year fish may be particularly affected, since recreational pulses are often requested during the warm summer months when newly hatched fish are rearing, whereas high flows in Californian rivers would commonly occur due to winter rains or spring snowmelt.

Strong pulsed flows may force juvenile salmonids downstream (McCrimmon 1954; Erman and Leidy 
1975; Ottaway and Clarke 1981; Ottaway and Forrest 1983; Heggenes and Traaen 1988; Crisp 1991; Crisp and Hurley 1991; Pearsons et al. 1992). Longitudinal displacement of juvenile coho salmon (Oncorhynchus kisutch) has been observed in streams during winter periods when floods are common (Shirvell 1994; Giannico and Healey 1998). However, the presence of complex habitat or coarse substrate may provide shelter to juvenile salmonids and minimize downstream displacement (Heggenes 1988; Bell et al. 2001). Older, larger fish may be less likely to be displaced downstream due to their increased swimming ability, relative to that of smaller fishes (Webb 1971). Rainbow trout (O. mykiss) (20-25 cm TL) were not displaced downstream by a spring flushing flow that increased discharge eight-fold (Simpkins et al. 2000).

There may be interactions between the impacts of flow releases and water temperature, or dissolved oxygen (Orth and Maughan 1982). Fish may seek deep pools in winter when water temperatures are low, and may thereby be protected from high flows in winter and late spring. During summer there may be a greater potential for high temperatures and low overnight dissolved oxygen concentrations that could interact with low flows. In a review of the impacts of peaking power on the survival of juvenile fish in the Columbia River basin, Bell et al. (1976) noted that rates of predation by piscivorous fish may be positively related to the temperature of water released from dams.

There may also be interactions between the seasonal timing and magnitude of pulse flow releases compared with normal flows for a given time of year, and the life history stage of fish present (Hunter 1992; Bradford et al. 1995; Saltveit et al. 2001). However, we found no previous studies that have addressed the effects of a single pulse on the distribution of youngof-the-year trout which would never have experienced a pulsed flow. Furthermore, we found no studies that have addressed the effects of a single pulse, with timing that was unseasonable for a Mediterranean climate, on the distribution of trout.

We studied the effects on fish of a 1 day pulse release from Camino Dam as condition of a FERC relicensing, designed to test the potential of Silver Creek for Class V whitewater kayaking. The aim of our study was to determine whether fish, particularly young-of-the-year, would be displaced downstream by this single pulsed flow that was over 38 times higher than the base flow and occurred in September, an unnatural time of year for a Mediterranean system.

\section{Study site}

Silver Creek is a tributary of the South Fork American River, central California. Water reaches the study section from Camino Reservoir, via Camino Dam (Fig. 1). Water flows into this reservoir from the upper part of Silver Creek, and, via the Jaybird Tunnel, from Union Valley Reservoir and Junction Reservoir. Water is stored in Camino Reservoir, and most of it is diverted through a series of tunnels to the Camino Powerhouse, from which it flows into the South Fork American River just upstream of Slab Creek Reservoir. Typically, a flow of about $0.5 \mathrm{~m}^{3} \cdot \mathrm{s}^{-1}$ is released from Camino Dam to Silver Creek to sustain fish, with occasional peaks up to $1-2 \mathrm{~m}^{3} \cdot \mathrm{s}^{-1}$. Discharge from Camino Dam to Silver Creek ranged between 0.25 and $2.11 \mathrm{~m}^{3} \cdot \mathrm{s}^{-1}$ from 1 October 2003 to 30 September 2004.

The section of Silver Creek that we studied was a bedrock reach (Bisson and Montgomery 1996). Mean wetted width at along the snorkel survey reach at baseflow was $8.4 \mathrm{~m}( \pm 4.5 \mathrm{SD})$, and the stream gradient was $2.7 \%$. The fifteen pools in the $300-\mathrm{m}$ long snorkel survey reach were at bedrock, but often contained some gravel, finer sediment, and fallen leaves. The habitat was relatively complex, with numerous boulders at the upper and lower boundaries of pools. The average maximum depth of the pools was $1.6 \mathrm{~m}$ ( $\pm 0.6 \mathrm{SD}$; range, 0.7-3.3 m; Table 1). Mean pool length was $16.5 \mathrm{~m}( \pm 10.1 \mathrm{SD}$; range, 5.5$37.2 \mathrm{~m}$ ), and average maximum pool width was $10.3 \mathrm{~m}$ ( $\pm 5.5 \mathrm{SD}$; range, 3.0-26.8 m). Mean pool area was $175 \mathrm{~m}^{2}\left( \pm 159 \mathrm{SD}\right.$; range, $\left.15-490 \mathrm{~m}^{2}\right)$. The total area of pools in the snorkel section was $2622 \mathrm{~m}^{2}$. The total length of all pools was $247 \mathrm{~m}$, comprising $82 \%$ of the habitat, with the remainder being cascades and runs.

\section{Methods}

We used a before-after study design and observed the distribution of trout before and after the pulse by snorkel surveys. This allowed us to observe all age 
Fig. 1 Location of study area on Silver Creek (a) within California, and $\mathbf{b}$ within the South Fork American River watershed. c Detail of study area showing sections of creek surveyed by radio-tracking and snorkeling
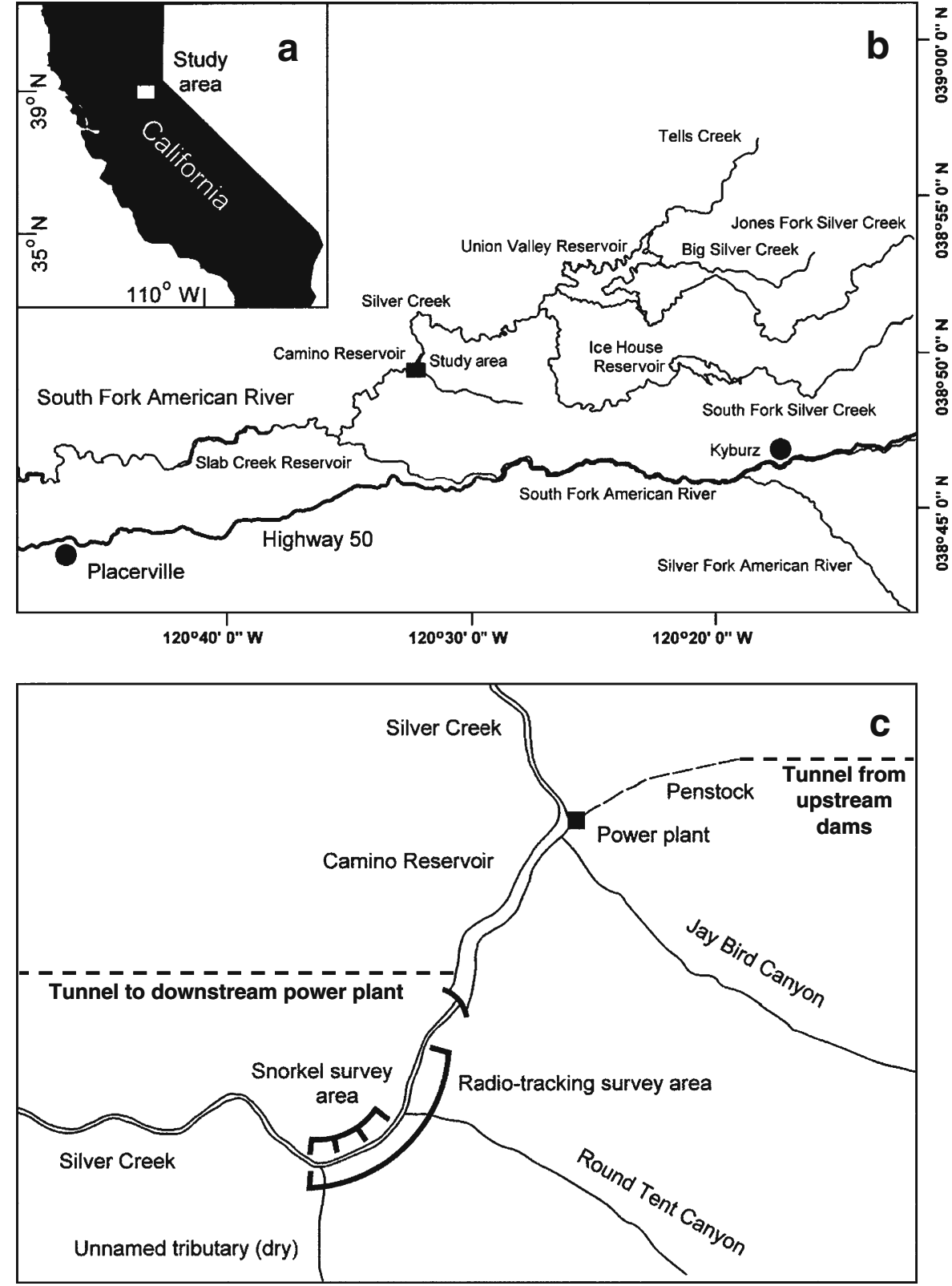

Table 1 Numbers of fish observed in the 300-m snorkel study area prior to and after the pulse, and percent change in observations

\begin{tabular}{llll}
\hline Age class & Pre-pulse & Post-pulse & Percent change \\
\hline Young-of-the-year & 39 & 29 & -26 \\
Juvenile & 76 & 69 & -9 \\
Adult & 25 & 28 & 12 \\
Total & 140 & 126 & -10 \\
\hline
\end{tabular}

classes, to determine whether smaller fish were more likely to be displaced downstream during a pulse. We also radio-tagged a small group of adult trout so that we could track the movement of individual fish before, during, and after the pulse. This allowed us to determine whether the fish observed in snorkel surveys after the pulse were likely to be the same individuals observed prior to the pulse (as opposed to fish washed into the study reach from further upstream). We marked some young-of-the-year and juvenile trout with visible implant elastomer, for the 
same purpose, but it was not possible to see the marks after the fish were released because of the distance between snorkelers and the fish (Klimley et al. 2005).

Flow values, measured at the outflow of Camino Dam, were provided by the Sacramento Municipal Utility District (SMUD). Daily average flow from Camino Dam into Silver Creek was obtained for the year from 1 October 2003 to 30 September 2004. Fifteen minute average flow was obtained for 15 September 2004. Flows in the study reach were probably slightly higher than the flow observed at the dam, since a small tributary joins Silver Creek just below the dam.

We measured water quality parameters in order to control for potential interactions with flow changes that might have affected fish distribution (Bell et al. 1976; Orth and Maughan 1982). Measurements of surface water temperature and dissolved oxygen concentration were made $500 \mathrm{~m}$ downstream of Camino Dam using a handheld meter (YSI, Model 550A) prior to, during, and after the 15 September 2004 pulsed flow. Triplicate water samples $(250 \mathrm{~mL}$ each) were collected at the same location prior to, during, and after the pulsed flow. Samples were analyzed for total Kjeldahl nitrogen (TKN), ammonia-nitrogen $\left(\mathrm{NH}_{4}-\mathrm{N}\right)$, nitrate-nitrogen $\left(\mathrm{NO}_{3}-\mathrm{N}\right)$, soluble phosphorus, and total phosphorus. Water quality analyses were performed by the University of California Division of Agriculture and Natural Resources Analytical Laboratory, on the UC Davis campus.

A preliminary snorkel survey performed on 24 August 2004 of all the pools within $500 \mathrm{~m}$ downstream of the dam indicated that there were very few young-of-the-year or juvenile fish. No fish less than $14 \mathrm{~cm}$ total length were observed in this part of the creek, so the 300-m snorkel survey reach was located between $500 \mathrm{~m}$ and $800 \mathrm{~m}$ downstream of the dam. Within the snorkel survey area pool length and maximum pool width were measured with a tape measure. Maximum pool depth was measured using a stadia rod. Measurements were made on 16 September 2004, at base flow.

We recorded fish snorkel counts in the 15 study pools on 14 September 2004 using established procedures (Dolloff et al. 1996), moving upstream through the study reach. Fish were identified to species where possible, or listed as "unknown". Fish length was estimated by eye in order to classify fish into age/size categories. Young-of-the-year fish were defined as those with total length less than $10 \mathrm{~cm}$. Juvenile fish were defined as those with total length of 10-18 cm. Adult fish were defined as those with total length greater than $18 \mathrm{~cm}$. On 16 September 2004 the pools were again surveyed by snorkeling to determine post-pulse locations and numbers of fish.

In order to provide a test of whether trout observed before and after the pulse were the same fish, rather than fish washed into the reach from upstream, we individually marked a group of adult trout. We captured one rainbow trout and six brown trout (Salmo trutta) for radio tracking from a 600-m reach that began about $200 \mathrm{~m}$ downstream of Camino Dam (Fig. 1). We used a larger section of the stream than we snorkeled, in order to increase the capture of fish large enough to radio tag. Fish were captured from 9 to 14 September 2004, by angling using artificial lures and insects, and tagged in the field. Standard lengths ranged between $20.5-28.2 \mathrm{~cm}$, and weights ranged between 118-360 g. Fish with a body mass between 105-225 g received a smaller tag (Lotek Wireless, NTC-4-2 L; $2.1 \mathrm{~g}, 8.3 \mathrm{~mm}$ diameter, $18.3 \mathrm{~mm}$ long; $93 \mathrm{~d}$ lifespan, $5 \mathrm{~s}$ pulse frequency) than fish with a body mass greater than $225 \mathrm{~g}$ (Lotek Wireless, NTC-6-2; $4.5 \mathrm{~g}, 9.1 \mathrm{~mm}$ diameter, $30.1 \mathrm{~mm}$ long; $126 \mathrm{~d}$ lifespan; $2.5 \mathrm{~s}$ pulse frequency). The tag weight did not exceed $2 \%$ of body weight (Jepsen et al. 2002).

Holding and recovery containers were treated with $10 \mathrm{~g} \cdot \mathrm{L}^{-1}$ rock salt to minimize fish stress by decreasing the osmotic gradient across the gills. Temperature and dissolved oxygen were monitored with a handheld meter (YSI, Model 550A). Fish were anesthetized with carbon dioxide anesthetic in a bucket (Peake 1998), then through a tube into the mouth during surgery. Tags were inserted intraperitoneally, with the whip antenna extending through a separate hole in the body wall. Each fish was allowed to recover in a mesh live trap in the stream, then released to the same pool from which it was captured.

Radio-tagged fish were tracked by walking along the bank using a hand-held 3-element Yagi antenna and a manual-tracking receiver (Lotek Wireless Inc., SRX400). Fish locations were determined (1) at the time of release, (2) pre-pulse (the day before the pulse), (3) during the pulse-flow release, and (4) postpulse (1 week after the pulse). Since our main interest was in whether these fish remained within the study 
reach, we recorded locations to the nearest pool. The location estimates have an error of approximately $\pm 13 \mathrm{~m}$ prior to and following the pulse release versus $\pm 25 \mathrm{~m}$ during the pulse flow period. At the base flow, there were 15 pools in the $300-\mathrm{m}$ snorkel reach, and each pool was approximately $20 \mathrm{~m}$ long, thus the error was estimated to be $\pm 13 \mathrm{~m}$. During the pulse the pools were larger and some merged together, so fish locations were recorded to within $\pm 25 \mathrm{~m}$.

One radio-tagged brown trout was not detected after being released. All other fish were observed during all subsequent tracking events. The distance moved by an individual fish between tracking events ranged from 0-120 $\mathrm{m}$ (Fig. 2). During the pulse flow event all six fish stayed within the 600-m study reach. Two fish moved upstream, three moved downstream, and one did not move.

\section{Results}

The flow out of Camino Dam was pulsed on 15 September 2004. The rate of discharge rose from $0.48 \mathrm{~m}^{3} \cdot \mathrm{s}^{-1}$ at $0600 \mathrm{~h}$ to $18.49 \mathrm{~m}^{3} \cdot \mathrm{s}^{-1}$ at $0945 \mathrm{~h}$, stayed constant until $1445 \mathrm{~h}$, and then dropped to $1.77 \mathrm{~m}^{3} \cdot \mathrm{s}^{-1}$ by $1730 \mathrm{~h}$, and $0.48 \mathrm{~m}^{3} \cdot \mathrm{s}^{-1}$ by $2030 \mathrm{~h}$ (Fig. 3). The water level in the creek increased about $1 \mathrm{~m}$ at the peak flow, as measured by a gage at the midpoint of the study reach.

Water temperature before and after the pulse was $10.7^{\circ} \mathrm{C}$. Values observed on the day of the pulse ranged between 10.2 and $10.9^{\circ} \mathrm{C}$. Dissolved oxygen

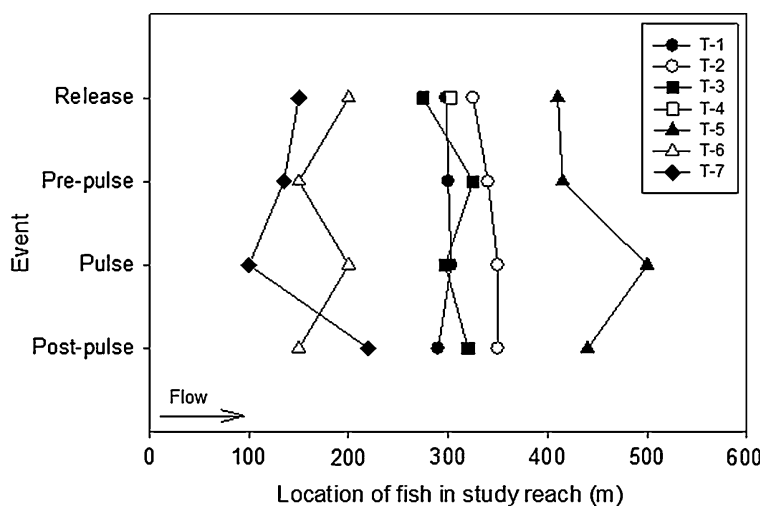

Fig. 2 Locations of radio-tagged fish at time of release, prepulse, pulse, and post-pulse. Symbols indicate location of fish along the study reach. Note: Camino Dam is $200 \mathrm{~m}$ upstream of the start of the study reach

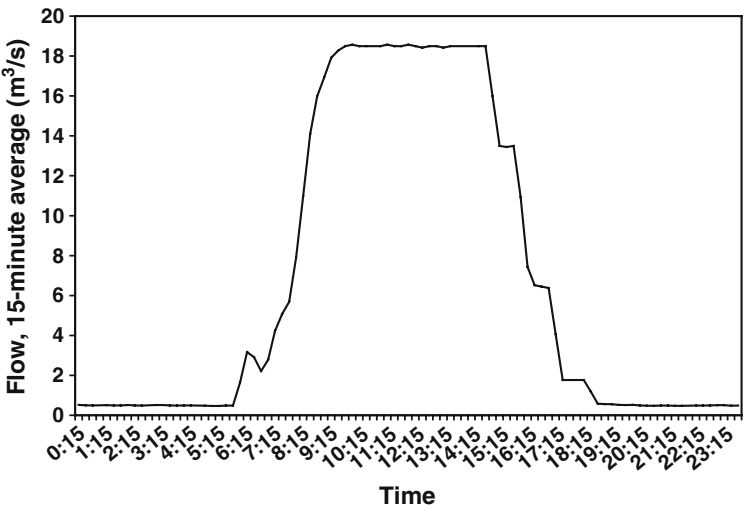

Fig. 3 Discharge from Camino Dam to Silver Creek during the pulse flow event on 15 September 2004. Values are $15 \mathrm{~min}$ average flows

was approximately $11 \mathrm{mg} \cdot \mathrm{L}^{-1}$ during the pulse, $9.64 \mathrm{mg} \cdot \mathrm{L}^{-1}$ the following day, and $10.67 \mathrm{mg} \cdot \mathrm{L}^{-1}$ on 21 September 2004, the final day of radio-tracking. Dissolved oxygen was not measured until 15 September at $1600 \mathrm{~h}$ due to a malfunction of the meter.

Total Kjeldahl nitrogen (TKN) values during the study ranged from below detection $\left(<0.1 \mathrm{mg} \cdot \mathrm{L}^{-1}\right)$ to $0.2 \mathrm{mg} \cdot \mathrm{L}^{-1}$. Ammonia-nitrogen $\left(\mathrm{NH}_{4}-\mathrm{N}\right)$ and nitratenitrogen $\left(\mathrm{NO}_{3}-\mathrm{N}\right)$ were below the detection limit $\left(<0.05 \mathrm{mg} \cdot \mathrm{L}^{-1}\right)$ in all samples. Soluble phosphorus (soluble P) was below the detection limit $\left(<0.05 \mathrm{mg} \cdot \mathrm{L}^{-1}\right)$ in all samples. Total phosphorus (total P) was below the detection limit $\left(<0.1 \mathrm{mg} \cdot \mathrm{L}^{-1}\right)$ in all samples.

Two species of fish were observed during snorkel surveys, rainbow trout, and non-native brown trout. Young-of-the-year, juveniles, and adults were observed for both species. A total of 140 fish were observed in the snorkel survey prior to the pulse flow release $(0.47 \mathrm{fish} /$ $\mathrm{m}$ ). The number of young-of-the-year trout (of both species) observed within the $300 \mathrm{~m}$ section declined $26 \%$ between the pre-pulse and post-pulse snorkel surveys (Table 1). Juvenile numbers declined 9\%, while adult numbers increased $12 \%$. Total trout density in each pool did not appear to differ markedly before and after the pulse (Fig. 4). The numbers of young-ofthe-year per pool tended to be lower after the pulse, but some groups of pools contained more young-of-theyear after the pulse (Fig. 5). Juvenile and adult fish numbers each increased in three pool groups, and declined in two pool groups, although the pattern was different for the two size classes. The total number of brown trout per pool ranged from 0-18 fish pre-pulse, 


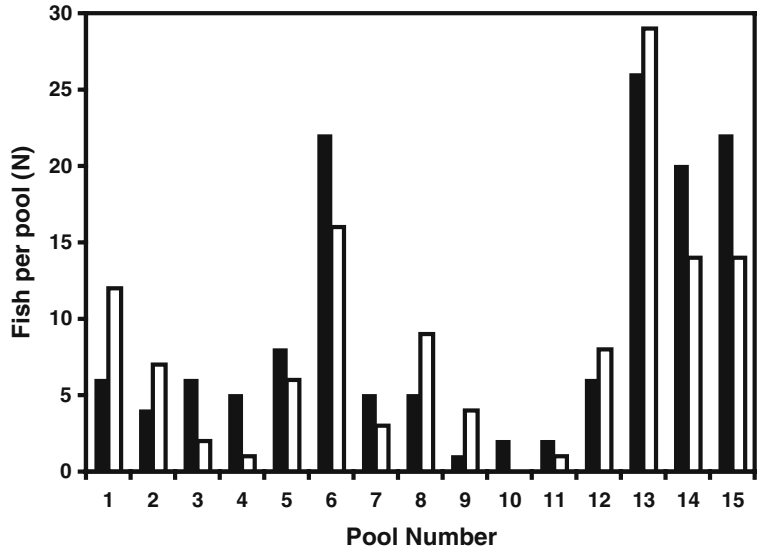

Fig. 4 Total number of brown trout and rainbow trout observed in snorkel counts of Silver Creek pools before and after the kayaking pulse flow event on 15 September 2004. Counts from 14 September 2004 in black, and 16 September 2004 in white. The experimental reach contained a total of fifteen pools, with Pool 1 at the upstream end of the section, and Pool 15 at the downstream end of the section
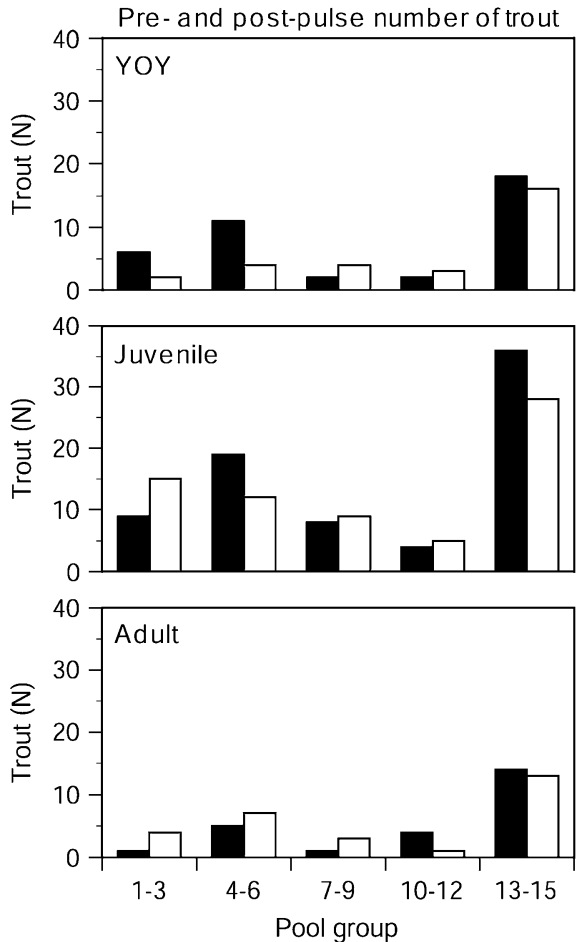

Fig. 5 Column on the left shows the number of trout, grouped by age, observed in snorkel counts of Silver Creek pools before and after the kayaking pulse flow event on 15 September 2004. Counts from 14 September 2004 in black, and 16 September 2004 in white. Column on the right shows the change in numbers of trout, grouped by age, after the pulse, in and 0-7 fish post-pulse, with the highest number of brown trout occurring in Pool 13 both pre- and postpulse. Rainbow trout were more abundant than brown trout in the study reach. While the total number of rainbow trout ranged from 1-20 fish pre-pulse, and 0 19 fish post-pulse, rainbow trout occurred in a higher proportion of pools than brown trout during both preand post-pulse.

\section{Discussion}

The majority of trout of all sizes observed in snorkel surveys did not experience catastrophic wash-out due to the pulse, or if they were displaced downstream, most had moved back upstream by the time of the post-pulse survey. Our results corroborate the observations of Salamunovich (2003) of fish response to pulsed recreational flow releases on the North Fork Feather River (California). Visual counts were made
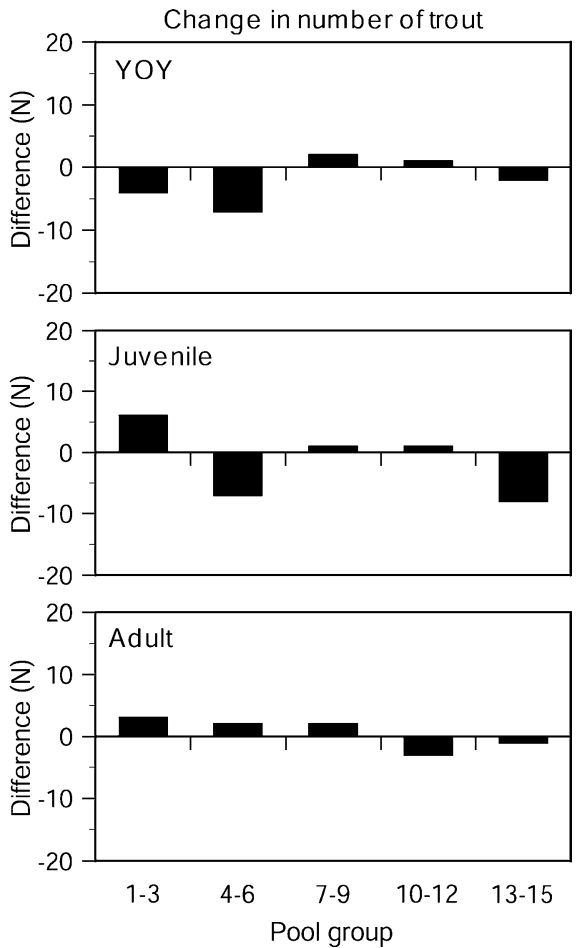

comparison with pre-pulse observations. The experimental reach contained a total of fifteen pools, with Pool 1 at the upstream end of the section, and Pool 15 at the downstream end of the section. Counts for pools were summed in groups of three to avoid having zero values in the pre-pulse data 
$24 \mathrm{~h}$ before and after the recreational flow releases. The study found little change in the observed species, number and sizes of fish before and after flow pulses.

However, our results also suggest that young-ofthe-year and juvenile trout may have been more susceptible than adult trout to being displaced downstream, since counts of these size classes were lower in the post-pulse snorkel than the pre-pulse survey. Downstream displacement of small trout by high water velocities has been observed previously (Ottaway and Clarke 1981; Ottaway and Forrest 1983), and if smaller fish were indeed displaced downstream in our study this may be due to their swimming performance being lower than that of larger fish, as suggested by Webb (1971). Heggenes and Traaen (1988) also found that smaller fish were more likely to be displaced downstream by increased discharge. Our results for larger fish are consistent with those of Simpkins et al. (2000) where rainbow trout over $20 \mathrm{~cm}$ TL were not displaced downstream by a spring flushing flow.

In our study water chemistry, temperature, and dissolved oxygen changed little during the pulse and were unlikely to have affected fish movement, leaving the flow change itself as the dominant factor. We caution that the complexity of habitat in Silver Creek, which has a large number of flow refugia (crevices, boulders, deep pools), may have mitigated the effects of the pulse, as has been observed in some prior studies (Bell et al. 2001; Nislow et al. 2002). However, there may have been indirect effects of the pulse in Silver Creek that we were unable to detect. The flow may have been sufficient to displace benthic macroinvertebrates, resulting in a decreased food supply for trout following the pulse (Lagarrigue et al. 2002). For safety reasons we were not able to observe the distribution of young-of-the-year trout during the pulse, but they may have been displaced out of preferred microhabitats, leading to decreased feeding and growth during the pulse (Korman and Campana 2009).

A source of uncertainty in our study is whether the fish we saw in the snorkel section during the postpulse survey were same as those observed prior to the pulse, or fish that had washed into the snorkel section from further upstream. However, the presence of the 6 radio-tagged adult trout within the study area before, during, and after the pulse suggests that the fish observed in the snorkel surveys were the same individuals before and after the pulse. Also, on 24 August 2004 we conducted a snorkel survey of the stream between the dam and the snorkel reach. We observed only 20 trout, all between 14-24 cm long, in the $500-\mathrm{m}$ long section $(0.04 \mathrm{fish} / \mathrm{m})$, suggesting that there were few fish that could have washed downstream to replace the fish that we counted prior to the pulse. We consider it unlikely that fish from upstream in Camino Reservoir or Silver Creek were entrained through Camino Dam during the pulse release and washed into the snorkel section. A site on Silver Creek, $1200 \mathrm{~m}$ upstream of Camino Reservoir, contained rainbow trout and brown trout in 2002, at densities similar to that of our snorkel reach (SMUD 2005b). However, during the pulse the water level in Camino Reservoir did not change appreciably, due to the combined operations of Jaybird Powerhouse and the outflow tunnel from the reservoir, so fish in upper Silver Creek would not have had any indication that flows were increasing out of the reservoir, and so would not have been attracted down into the reservoir. Little is known about the fish species and densities occurring within Camino Reservoir itself. During a SMUD hydropower re-licensing study conducted in 2002-2003 Camino Reservoir was removed from the study due to safety and access constraints (SMUD 2005a). The authors noted historic reports, some undated, which listed the fish species in Camino Reservoir as California roach, brook trout, brown trout, rainbow trout, riffle sculpin, Sacramento sucker, and "minnows". Camino Reservoir has surface water temperatures and dissolved oxygen levels suitable for trout (SMUD 2004). However, SMUD staff who have fished for trout in both Camino Reservoir and in Silver Creek downstream of Camino Dam reported that they have observed few trout in the reservoir.

A problem for our study was the lack of a robust experimental design, which limited our ability to make statistical inferences about our observations, as is common for studies of the effects of flow regulation on fish (Murchie et al. 2008). The observation of single pulses on multiple streams with comparable fish fauna, over the same time period, would have provided true replication, but such pulsed flows were not occurring on nearby streams. We could have observed multiple sub-reaches along Silver Creek, but since fish could have moved between the sub-reaches these "replicates" would not have been independent and would have resulted in a pseudoreplicated design 
(Hurlbert 1984). Furthermore, the sub-reaches would have been located along a gradient of distance from the dam, and of decreasing elevation, causing autocorrelation that would have further complicated analyses. Our design would also have benefited from one or more control reaches (Carpenter 1990), thus allowing a BACI design (Underwood 1992), but flows in the reach of Silver Creek immediately upstream of Camino Reservoir are influenced by other dams and reservoirs further upstream (see Fig. 1b). It would have been possible for us to conduct repeated daily snorkel surveys over several days prior to the pulsed flow, in order to have an estimate of the variability of our counts, and to see whether the count immediately after the pulse was statistically different. However, we were concerned that the repeated disturbance of the fish for several days prior to the pulse might have decreased their activity levels and feeding rates and affected their response to the pulse itself. As future FERC relicensing studies occur in California streams opportunities may arise to repeat the observation of trout response to single-day pulses, and to pool the results of these studies for meta-analysis.

This study highlights several areas of uncertainty regarding the effects of single pulsed flows. First, the pulse flow release occurred in September, when young-of-the-year trout were well-developed and likely able to locate and move to low velocity areas to avoid the higher flows, allowing a majority to remain within the study reach. It would be informative to test pulses of similar magnitude at other times of the year, such as early summer, when fry may be newly emerged, and less able to locate and use flow refugia. Second, the habitat in Silver Creek is relatively complex and heterogeneous, which likely provided a wide variety of flow refugia for fish. It would be useful to test the impacts of a similar pulse in streams with poorer habitat to see whether fish are more likely to be displaced as habitat complexity declines. Third, the fish community in Silver Creek is very simple, and is likely compromised mainly of the two trout species that we observed. A similar magnitude pulse might have more dramatic impacts in streams with a greater number of species that prefer slower velocities than those preferred by trout. This could be tested in conjunction with tests of the effect of seasonality and habitat complexity.
Acknowledgements This study was funded by the Public Interest Energy Research Program of the California Energy Commission through the Pulsed Flow Program of the Center of Aquatic Biology and Aquaculture of the University of California, Davis. We also acknowledge support from the Division of Water Rights of the State Water Resources Control Board. We thank the Sacramento Municipal Utility District for providing information on creeks that were scheduled for pulsed flows, for assistance during the field work at Silver Creek, and for providing flow data for Camino Dam releases to Silver Creek. We received helpful comments on the manuscript from three anonymous reviewers.

Open Access This article is distributed under the terms of the Creative Commons Attribution Noncommercial License which permits any noncommercial use, distribution, and reproduction in any medium, provided the original author(s) and source are credited.

\section{References}

Bell E, Duffy WG, Roelofs TD (2001) Fidelity and survival of juvenile coho salmon in response to a flood. Trans Am Fish Soc 130:450-458

Bell MC, Parkhurst ZE, Porter RG, Stevens M (1976) Effects of power peaking on survival of juvenile fish at lower Columbia and Snake River dams. U.S. Army Corps of Engineers, North Pacific Division (Contract No. DACW 57-75-C-0173), Portland, Oregon, USA. 35 p

Bisson PA, Montgomery DR (1996) Valley segments, stream reaches, and channel units. In: Hauer FR, Lamberti GA (eds) Methods in stream ecology. Academic, San Diego, pp 23-52

Bradford MJ, Taylor GC, Allan JA (1995) An experimental study of the stranding of juvenile coho salmon and rainbow trout during rapid flow decreases under winter conditions. N Am J Fish Manage 15:473-479

Carpenter SR (1990) Large-scale perturbations: opportunities for innovation. Ecology 71:2038-2043

Crisp DT (1991) Stream channel experiments on downstream movement of recently emerged trout, Salmo trutta L. and salmon, S. salar L.- effects of developmental stage and day and night on dispersal. J Fish Biol 39:371-381

Crisp DT, Hurley MA (1991) Stream channel experiments on downstream movement of recently emerged trout, Salmo trutta L. and salmon, Salmo salar L.-1. Effect of four different water velocity treatments upon dispersal rate. J Fish Biol 39:347-361

Dolloff A, Kershner J, Thurow R (1996) Underwater observation. In: Murphy BR, Willis DW (eds) Fisheries techniques, 2nd edn. American Fisheries Society, Bethesda, Maryland, pp 533-554

Erman DC, Leidy GR (1975) Downstream movement of rainbow trout fry in a tributary of Sagehen Creek, under permanent and intermittent flow. Trans Am Fish Soc 104:467-473

Giannico GR, Healey MC (1998) Effects of flow and food on winter movements of juvenile coho salmon. Trans Am Fish Soc 127:645-651 
Heggenes J (1988) Effects of short-term flow fluctuations on displacement of, and habitat use by, brown trout in a small stream. Trans Am Fish Soc 117:336-344

Heggenes J, Traaen T (1988) Downstream migration and critical water velocities in stream channels for fry of four salmonid species. J Fish Biol 32:717-727

Hunter MA (1992) Hydropower flow fluctuations and salmonids: a review of the biological effects, mechanical causes and options for mitigation. Washington Department of Fisheries Technical Report 119. Olympia, Washington

Hurlbert SH (1984) Pseudoreplication and the design of ecological field experiments. Ecol Monogr 54:187-211

Jepsen N, Koed A, Thorstad EB, Baras E (2002) Surgical implantation of telemetry transmitters in fish: how much have we learned? Hydrobiol 483:239-248

Klimley AP, Cech, Jr JJ, Thompson LC, Hamilton S, Chun SN (2005) Experimental and field studies to assess pulsed, waterflow impacts on the behavior and distribution of fishes in California rivers, annual report, 2004-05. Prepared for the PIER Program Area, California Energy Commission. 107 p http://www.energy.ca.gov/publications/displayOneReport. php?pubNum $=$ CEC-500-2005-172

Klimley AP, Cech, Jr JJ, Thompson LC, Hamilton S (2007) Experimental and field studies to assess pulsed, water flow impacts on the behavior and distribution of fishes in the South Fork of the American River, II (Second Year). University of California, Davis, for the California Energy Commission, PIER Energy-Related Environmental Research. $85 \mathrm{p}$ http://animalscience.ucdavis.edu/PulsedFlow/ Klimley\%20500-09-067.pdf

Korman J, Campana SE (2009) Effects of hydropeaking on nearshore habitat use and growth of age- 0 rainbow trout in a large regulated river. Trans Am Fish Soc 138:76-87

Lagarrigue T, Cereghino R, Lim P, Reyes-Marchant P, Chappaz R, Lavandier P, Belaud A (2002) Diel and seasonal variations in brown trout (Salmo trutta) feeding patterns and relationship with invertebrate drift under natural and hydropeaking conditions in a mountain stream. Aquat Living Resour 15(2):129-13

McCrimmon H (1954) Stream studies on planted Atlantic salmon. J Fish Res Bd Can 11:362-403

Murchie KJ, Hair KPE, Pullen CE, Redpath TD, Stephens HR, Cooke SJ (2008) Fish response to modified flow regimes in regulated rivers: research methods, effects and opportunities. River Res Applic 24:197-217

Nislow KH, Magilligan FJ, Folt CL, Kennedy BP (2002) Within-basin variation in the short-term effects of a major flood on stream fishes and invertebrates. J Freshwater Ecol 17(2):305-318

Ottaway EM, Clarke A (1981) A preliminary investigation into the vulnerability of young trout (Salmo trutta L.) and Atlantic salmon (S. salar L.) to downstream displacement by high water velocities. J Fish Biol 19:135-145
Ottaway EM, Forrest DR (1983) The influence of water velocity on the downstream movements of alevins and fry of brown trout, Salmo trutta L. J Fish Biol 23:221-436

Orth DJ, Maughan OE (1982) Evaluation of the incremental methodology for recommending instream flows for fishes. Trans Am Fish Soc 111:413-445

Peake S (1998) Sodium bicarbonate and clove oil as potential anesthetics for non-salmonid fishes. North Am J Fish Manage 18:919-924

Pearsons TN, Li HW, Lamberti GA (1992) Influence of habitat complexity on resistance to flooding and resilience of stream fish populations. Trans Am Fish Soc 121:427-436

SMUD (Sacramento Municipal Utility District) (2004) Sacramento Municipal Utility District's Upper American River Project (FERC Project No. 2101). Deepwater intake entrainment technical report, July 2004, $54 \mathrm{p}$

SMUD (Sacramento Municipal Utility District) (2005a) Sacramento Municipal Utility District's Upper American River Project (FERC Project No. 2101) and Pacific Gas and Electric Company's Chili Bar Project (FERC Project No. 2155). Stream fisheries technical report, January 2005, version 2, $180 \mathrm{p}$

SMUD (Sacramento Municipal Utility District) (2005b) Sacramento Municipal Utility District's Upper American River Project (FERC Project No. 2101) and Pacific Gas and Electric Company's Chili Bar Project (FERC Project No. 2155). Reservoir fisheries technical report, April 2005, version $2,83 \mathrm{p}$

Salamunovich T (2003) Rock Creek-Cresta (FERC No. 1962) recreation and pulse flow biological evaluation: stranding and displacement studies. Draft report of Thomas R. Payne and Associates, Arcata, CA to Pacific Gas and Electric Company, San Ramon, CA

Saltveit SJ, Halleraker JH, Arnekleiv JV, Harby A (2001) Field experiments on stranding in juvenile Atlantic salmon (Salmo salar) and brown trout (Salmo trutta) during rapid flow decreases caused by hydropeaking. Regul River 17:609-922

Shirvell CS (1994) Effect of changes in stream flow on the microhabitat use and movements of sympatric juvenile coho salmon (Oncorhynchus kisutch) and chinook salmon (O. tshawytscha) in a natural stream. Can J Fish Aquat Sci 51:1644-1652

Simpkins DG, Hubert WA, Wesche TA (2000) Effects of a spring flushing flow on the distribution of radio-tagged juvenile rainbow trout in a Wyoming tailwater. North Am J Fish Manage 20:546-551

Underwood AJ (1992) Beyond BACI: the detection of environmental impacts in the real, but variable, world. $\mathrm{J}$ Exp Mar Bio Ecol 161:145-178

Webb PW (1971) The swimming energetics of trout. I. Thrust and power at cruising speeds. J Exp Biol 55:489-500 